\title{
0535 HEAD INJURIES, FACTORS ASSOCIATED, OUTCOMES
}

D Busingye* E Bua Correspondence: School of Medicine, College of Health sciences, Makerere University, C/O Miss Tugumisirize Tophers, Ministry of Finance, P.O BOX 8147 Kampala +256, Uganda

10.1136/ip.2010.029215.535

\begin{abstract}
Introduction Road traffic accidents are a major cause of injury and trauma in Uganda, of which head injuries are a major cause of morbidity and mortality among casualties.

Objectives To determine the leading cause of head injuries, factors associated and the outcomes.

Methods A retrospective study was carried out. Pretested questionnaires were filled in from the Records department on patients with head injuries in the years 2007, 2008 and 2009. Data was entered using Epi data software, cleaned and exported to SPSS for analysis in Respect to the study variables.

Results The median age was found to be $28.90 \%$ were as a result of road traffic accidents of which $86 \%$ were motorcyclists. Most injuries occurred between $8 \mathrm{pm}$ and $2 \mathrm{am}$. Trend showed Increase in the number of injuries and complications thereafter.

Conclusion The increase in the number of head injuries among young energetic men causes a strain on the country's labour and resources. There is great need for education and public awareness on the traffic rules, provision of protective gear to the cyclists and passengers and reduction of motorcycles in the city.
\end{abstract}

